\title{
Histological and Ultrastructural Study Of Silver Nanoparticles Toxicity and The Possible Protective Effect Of Vitamin C On Submandibular Salivary Glands Of Albino Rats
}

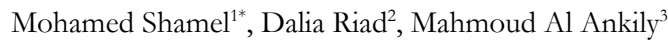

${ }^{1}$ Dentistry, Oral Biology, The British University in Egypt Shorouk city, 11837, Egypt.

${ }^{2}$ Dentistry, Oral Biology, Beni-Suef University Beni-Suef, 62511, Egypt.

${ }^{3}$ Dentistry, Oral Biology, The British University in Egypt Shorouk city, 11837, Egypt.

\section{Abstract}

Introduction: Despite silver nanoparticles (AgNPs) beneficial effect in many fields, it has been shown that AgNPs can induce toxic effects. Cytotoxic effect of AgNPs is related to the increased release of reactive oxygen species (ROS) which may lead to cell death. Natural antioxidant scavengers like vitamin $\mathrm{C}$ have the capacity to bind and neutralize ROS thus having a vital role in cellular defense against oxidative stress.

Objective: The objective of the current study was to assess the cytotoxic impact of AgNPs on the submandibular salivary glands of Albino rats and to reveal the potential antioxidant influence of vitamin C to counteract this toxicity.

Materials and methods: Eighteen albino rats were used in this study and were divided in to three groups, group I: control group, group II: Rats injected with AgNPs in a dose of $2 \mathrm{mg} / \mathrm{kg}$ once daily for 28 days and group III: rats injected with AgNps as in group II in addition to vitamin C in a dose of $100 \mathrm{mg} / \mathrm{kg}$. Histological and ultrastructural examinations were performed on the dissected submandibular salivary glands.

Results: Histological and ultrastructural results showed destructive changes to the acini and ducts of the submandibular salivary glands of rats receiving AgNPs. In group III which received vitamin C, nearly normal histological and ultrastructural features were observed in the parenchymal elements of the glands.

Conclusions: AgNPs produced substantial toxic histopathological changes in the submandibular salivary glands of albino rats while the administration of vitamin $\mathrm{C}$ has proven to be effective in counteracting these toxic effects through its powerful antioxidant properties.

Keywords: Silver Nanoparticles; Vitamin C; Antioxidant; ROS; Salivary Glands.

\section{Introduction}

Nanoparticles (NPs) are accumulation of atoms and molecules of size ranging between 1-100 $\mathrm{nm}$ [1]. They can show a wide range of properties that are size-dependent. NPs are generally classified based on their size, shape, composition, uniformity and agglomeration in to four main groups: metal based, carbon based, dendrimers and composites. Metal NPs such as iron and titanium oxides, as well as gold and silver NPs have been widely used as diagnostic and therapeutic agents [2].
Among these metals, silver nanoparticles (AgNPs) are more popular than other metals due to their prospective uses in commercial products. AgNPs have been considered a forefront material because of their outstanding properties rendering them to act differently from those of other metals. The fundamental prominent feature of AgNPs is its great surface area to volume ratio, thus permitting the nanomaterials to be broadly used in many fields such as biotechnology, biomedical sciences, biosensors, health care, household products, agriculture and the food industry [3-6].

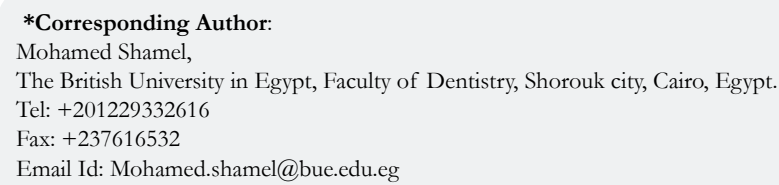

Citation: Mohamed Shamel, Dalia Riad, Mahmoud Al Ankily. Histological and Ultrastructural Study Of Silver Nanoparticles Toxicity and The Possible Protective Effect Of Vitamin C On Submandibular Salivary Glands Of Albino Rats. Int J Dentistry Oral Sci. 2021;08(04):2166-2171. doi: http://dx.doi.org/10.19070/2377-8075-21000428 
Despite AgNPs beneficial effect in many fields, it has been shown that AgNPs can induce cytotoxic effects to different organs. Several studies showed that, due to their nano size, AgNPs can easily pass through cell membranes and causes toxicity with in various tissues $[7,8]$.

Several theories have been stated to demonstrate the mechanism of AgNPs toxicity. One of the proposed theories is the formation of reactive oxygen species (ROS) following the release of $\mathrm{Ag}$ ions intracellularly. Ag ions release cause toxicity by what is called Trojan-horse mechanism, where AgNPs are taken by body's cells then release Ag ions intra-cellularly, which eventually leads to cell death through oxidation of proteins as well as through mitochondrial and DNA damage $[9,10]$.

Zapór, (2016) investigated the cytotoxic effect of AgNPs on both reproductive and pulmonary cells. He evaluated the AgNPs effect on cell viability, the integrity of cell membrane, the metabolic activity of mitochondria and oxidative DNA damage. Results showed that AgNPs had a powerful cytotoxic effect at low concentration and led to increase in the ROS levels even at these low concentrations. This increased ROS caused oxidative damage in the DNA of cells and subsequently cell death [11].

According to the suggested oxidative stress theory, the minimum amount of ROS triggered by the NPs may lead to some protective responses from the body cells such as the induction of antioxidants. If the balance between the antioxidants and the formed ROS fails, the oxidative stress induces inflammation and triggers failure in mitochondrial function, resulting in cellular death. So endogenous and dietary antioxidants are considered as the first line of defense $[12,13]$, due to their potential to act as protective agents against destruction caused by various types of NPs through lowering down the ROS level $[14,15]$.

Natural antioxidant scavengers like vitamin $C$ have the capacity to bind and neutralize ROS produced intracellularly which ultimately lead to avoiding lipid oxidation and mitochondrial permeability and thus having a vital role in cellular defense against oxidative stress [16].

Various studies showed that AgNPs can cause toxicity following different routes of exposure. Consequently, the objective of the current study was to assess the cytotoxic effect of intraperitoneal injection of AgNPs on the submandibular salivary glands and to reveal the potential antioxidant influence of vitamin $C$ to counteract this toxicity.

\section{Materials and Methods}

\section{Animals}

Ethical approval for the experimental procedures was obtained from the ethical and scientific committee of Faculty of Dentistry, Ain Shams University, Egypt. Eighteen adult male albino rats, 5-6 months old and average weight of $150-200 \mathrm{gms}$, were used in this study. Before conducting the study the rats were adapted to their cages for one week. The rats were kept in a controlled environment and had free access to food and water. Sample size was computed using G*Power software version 3.1.9.6 (University Kiel, Germany) [17] and the sample size was estimated to be a total of
18 for three groups.

\section{Grouping}

The rats were equally and randomly divided in to the following groups:

Group I: Acted as a control group and rats received intraperitoneal (IP) injections of distilled water for 28 days.

Group II: Rats received IP injections of $\mathrm{AgNPs}$ (size $45 \pm 5 \mathrm{~nm}$ ), in a dose of $2 \mathrm{mg} / \mathrm{kg} / \mathrm{B}$.W once daily for 28 days [18].

Group III: Rats received IP injections of AgNPs as in the previous group, and at the same time administration of vitamin $\mathrm{C}$ via oral route in a dose of $100 \mathrm{mg} / \mathrm{kg} / \mathrm{B}$.W in drinking water daily for 28 days [19].

AgNPs were purchased from Nano Gate Company, Egypt with size $40 \pm 5 \mathrm{~nm}$. Vitamin C was provided by Vitabiotics company, Egypt.

\section{Preparation and Staining Of Specimens}

The rats were sacrificed by euthanization followed by cervical dislocation at the end of the study periods. Both right and left submandibular salivary glands of the sacrificed rats were dissected out and were prepared for light microscopic and ultrastructural examination through Hematoxylin and eosin stain and transmission electron microscope respectively. Light microscopic sections were mounted and examined with ZEISS Primo Star light microscopy in Faculty of Dentistry, the British university in Egypt. The prepared ultra-thin sections were examined by JEOL JEM 1400 Transmission Electron Microscope; Jeol Ltd, Tokyo, Japan in TEM lab, Cairo University -Research Park, Egypt.

\section{Results}

\section{Histological Results}

Group I: Light microscopic investigation of the submandibular salivary glands of Group I showed that the gland architecture was histologically normal where it consisted of serous acini and ductal systems. The serous acini appeared spherical in shape and lined with pyramidal cells lining a narrow lumen and with basophilic cytoplasm and basally situated rounded nuclei. The components of the ductal system were the intercalated, striated and excretory ducts as well as granular convoluted tubules which all appeared with normal histological features (Figure 1).

Group II: Histological examination of the AgNPs group displayed marked degeneration in the parenchymal elements of submandibular salivary gland. The serous acini showed shrinkage and degeneration with numerous cytoplasmic vacuolations. Degenerated nuclei manifested as Pyknotic and crescent-shaped figures were found frequently within the degenerated acinar cells. Some red blood cells extravasation was seen in between the serous acini. Striated ducts showed loss of basal striations in addition to vacuolations which were frequently observed in the cells of the duct as well in cells of the granular convoluted tubules. Stagnated secretion and loss of normal cell lining was observed in the excretory 
ducts (Figure 2).

Group III: Histological examination of the recovery group showed marked improvement of their histological picture in comparison to those of the silver nanoparticles group. Acini appeared spherical in shape and lined by pyramidal shaped cells with no or just few vacuolations. The striated duct regained its basal striations and apparently less vacuolations were observed in the duct as well as in the granular convoluted tubules in comparison to group II. Excretory ducts possessed a pseudo stratified lining with no stagnated secretion (Figure 3).

\section{Ultrastructural Results}

The electron microscopic examination of the submandibular glands of control group showed acini with narrow lumen and the pyramidal cells appeared with normal organelles. Striated duct cells had basal striations and contained normal nuclei and elongated mitochondria. The granular convoluted tubules had well circumscribed apically located membrane bound granules with various electron densities (Figure 4).

AgNPs group revealed that the secretory cells showed marked atrophic changes. There was accumulation of electron-lucent secretory granules, a lot of shrunken nuclei, marked dilation of rough endoplasmic reticulum (RER), a lot of cytoplasmic vacuolations, marked cell organelle degeneration, and destroyed and ruptured mitochondria which lost their cisternae. The intercalated and striated ducts and the granular convoluted tubules showed multiple intracytoplasmic vacuoles representing damaged areas of cytoplasm with severe loss of cell organelles (Figure 5).

Specimens of vitamin $\mathrm{C}$ group revealed marked improvement in comparison to those of the silver nanoparticles group with mild

Figure 1. Photomicrographs (H\&E original magnification X400) of submandibular salivary gland from the control group showing A: serous acini lined by pyramidal cells having basophilic cytoplasm and basally situated rounded nuclei, B: striated duct (ST) with basal striations (arrows), C: normal striated duct (ST) and granular convoluted tubule (GCT), Excretory duct with normal pseudo stratified columnar lining and surrounding connective tissue.

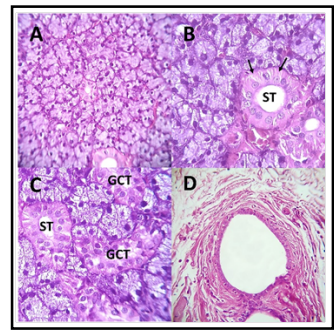

Figure 2. Photomicrographs (H\&E original magnification x400) of submandibular salivary gland from the AgNPs group showing A: degenerated serous acini and striated ducts with different sized vacuoles (black arrows) and areas of degeneration (asterisks) in between the acini, B: degenerated acini with numerous vaculations (black arrows), degenerated striated ducts (ST) and extravasated RBCs between the acini were also noted (red arrows), C: degenerated granular convoluted tubule (GCT) and striated duct (ST), areas of degeneration (asterisks) can be noted, D: Excretory duct with degenerated cell lining and vacuoles (arrows), surrounding connective tissues stroma showed degeneration (asterisk).

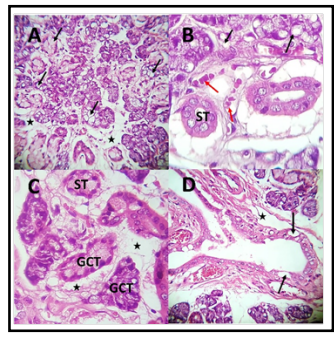

Figure 3. Photomicrographs (H\&E original magnification $\mathrm{x} 400)$ of submandibular salivary gland from the vitamin $\mathrm{C}$ group showing A: apparently normal serous acini with well-defined outline lined by pyramidal cells with rounded nuclei and striated ducts (ST) with normal cell lining, small areas of degeneration can be noted (asterisks), B: striated ducts (ST) with basal striations (arrows), some areas of degeneration can be seen (asterisk), C: Normal acini and granular convoluted tubule (GCT), D: normal lining of excretory duct and some stagnated secretion can be seen.

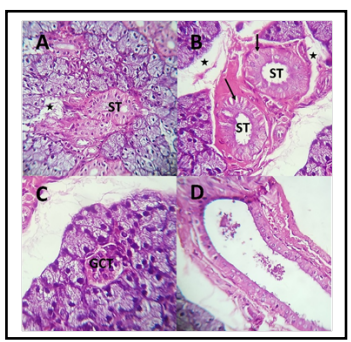


Figure 4. Electron micrographs of submandibular salivary gland from the control group showing A: serous acinus with pyramidal cells surrounding a narrow lumen $(\mathrm{L})$ with normal nucleus $(\mathrm{N})$. Secretory granules (SG) located apically and normal mitochondria (arrows) were also seen in the striated duct (arrow head) (X5000), B: acinar cell with normal nucleus (N) and rough endoplasmic reticulum (arrows) and numerous secretory granules (SG) (X12000), C: striated duct cell with normal nucleus (N) and normal mitochondria (arrow) (X12000), D: Granular convoluted tubules with normal mitochondria (arrows) and numerous electron dense secretory granlules (Original magnification X 12000).

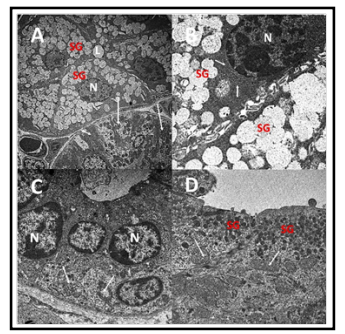

Figure 5. Electron micrographs of submandibular salivary gland from AgNPs group showing A: acinar cells with degenerated nuclei (N) and numerous vaculations (arrows) (X5000), B: acinar cell with degenerated nucleus (N) with irregular nuclear membrane and dilated cisternae of RER (arrow) (X12000), C: striated duct with degenerated nucleui (N), numerous vaculations (white arrows) and degenerated mitochondria (yellow arrows) (X12000), D: Granular convoluted tubules with numerous vaculations (arrows) (X12000).

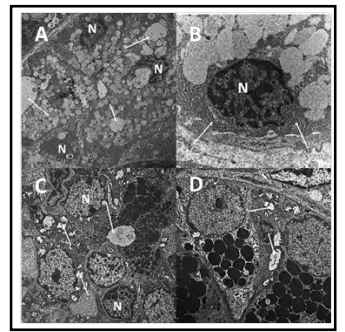

Figure 6. Electron micrographs of submandibular salivary gland from the Vitamin C group showing A: serous acinus with pyramidal cells surrounding a narrow lumen (L) with normal nucleus (N) and secretory granules (SG) located apically (X5000), B: acinar cell with normal nucleus (N) and rough endoplasmic reticulum (arrows) (X12000), C: striated duct cell with normal nucleus (N) and normal mitochondria (arrow) (X12000), D: Granular convoluted tubules with normal nucleus

(N), mitochondria (arrows) and numerous electron dense secretory granules (SG) (X12000).

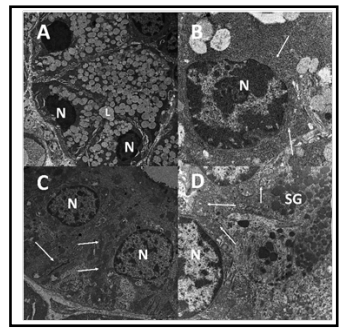

ultrastructural alterations manifested as few vacuolations (Figure 6).

\section{Discussion}

Due to its widespread use, AgNPs toxicity in different tissues has been investigated in many studies and has been shown to be cytotoxic even at low doses. The main pathways of exposure to NPs are usually through ingestion, inhalation, dermal contact and also through intraperitoneal or intravenous injection. Accordingly, the current study aimed to investigate the toxic effects of intraperitonealinjecton of AgNPs on the submandibular salivary glands of Albino rats and the possible protective effect of vitamin C.

The AgNPs sizes used in the current study were also recommended by Osborne et al (2013) [20] who stated that small nano particles sizes were found to be more toxic than the larger particle sizes as they are able to cross the basement membrane and accumulate in body tissues.

In the present study, the results showed histopathological changes in the parenchymal elements of the glands. These changes were apparent shrinkage and degeneration with abundant cytoplasmic vacuolations in the serous cells as well as in the ducts, suggesting that AgNPs have a potential to induce cytotoxic effects intracellularly.

Similar histological changes were also observed by Sarhan and Hussein (2014) [21] where the renal cortex in kidney tissue from albino rats intoxicated with AgNPs via intraperitoneal injection, showed swollen epithelium and cytoplasmic vacuolations, with some nuclei showing hypertrophied nucleoli. The authors attributed this to the generation of ROS which is associated with increased oxidative stresses and cytotoxic events. 
Our results also coincide with those obtained by Taha and Mahmoud (2019) [22] who reported that the ducts of the parotid salivary glands of albino rats were reduced with wide lumen having vacuolated, degenerated and thick epithelial lining and lost their cellular lining after oral administration of silver nanoparticles.

The ultrastructural results of this study showed degenerated acini and ducts with numerous vacuoles in the parenchymal cells. The mostly affected organelle was the mitochondria which appeared severely degenerated in both the acini and striated ducts. Degenerated mitochondria are considered to be a sign of toxicity leading to cell death [23]. Moreover degenerated nuclei as well as widening in the rough endoplasmic reticulum were frequently observed within the cells. The ultrastructural results are in agreement with the study performed by Taghyan et al., 2020 [24] which showed that the parotid gland acinar and ductal cells of the rats which were injected with AgNPs, showed signs of toxicity as degenerated nuclei and mitochondria in addition to cytoplasmic vacuolations and dilated rough endoplasmic reticulum.

Our results also agreed with those obtained by Sarhan and Hussein (2014) [21] where their ultrastructural results of the livers of the albino rats after administration of silver nanoparticles showed hepatocytes with numerous cytoplasmic vacuolations, degenerated mitochondria and with fewer stacks of fragmented rough endoplasmic reticulum cisternae. The authors explained that the AgNPs caused destruction of the mitochondrial membrane and decrease in the production of adenosine triphosphate leading to metabolic and cell cycle arrest, and subsequently to extensive cell death.

These results could be furtherly explained by Ma et al (2015) [25] who reported that silver nanoparticles cause increased accumulation of ROS within neuronal cells and thus induce mitochondrial membrane depolarization and subsequently damage.

Our findings were also described by Asharni et al (2009) [9] where they stated that silver nanoparticles can damage DNA and cause chromosomal aberrations which is mainly caused by increased levels of ROS.

Liu et al (2010) [26], provided an evidence that links between increase of AgNPs in cells and elevated ROS and hence increase in oxidation stress and cytotoxicity. Accordingly using of antioxidants could prevent or slow damage to cells caused by ROS. The antioxidant which were used in the present study was vitamin $\mathrm{C}$ which is commonly used nowadays as a powerful antioxidant [27]. In the current study, the submandibular salivary glands of group II which received vitamin $\mathrm{C}$, showed almost regular histological and ultrastructural features. These findings may be explained by the study performed by Guo et al., 2013 which reported vitamin $\mathrm{C}$ as an effective ROS scavenger and as an efficient silver chelating agent. The study concluded that vitamin $\mathrm{C}$ can completely reverse the generation of ROS and could considerably prevent DNA damage with in the cells suggesting that silver toxicity can be reduced by silver ion chelation [28].

Another study by Suliman et al., (2015) [29] examined the effect of vitamin $\mathrm{C}$ against the toxicity induced by AgNPs. This in vitro study using human lung epithelial cells which were exposed to
AgNPs in the presence of vitamin C, showed that the vitamin had the ability to eliminate the cytotoxic effect of AgNPs and regain the cell viability. The protective effect of vitamin $\mathrm{C}$ was attributed to its powerful antioxidant property.

Moreover, in the ultrastructural results of group III, there was obvious reduction in the cellular vacuolations in the acinar and ductal cells in comparison to group II. Cellular organelles such as nuclei, mitochondria and RER were present almost normally. These organelles are considered crucial elements to keep the integrity of the cells.

The ultrastructural findings in the current study could be explained by what was concluded by Teodoro et al., (2016) who stated in their study that the toxic effects of $\mathrm{Ag}$ on mitochondria can be counteracted by the use of powerful antioxidant scavengers like vitamin C [30]. Mitochondria is a fundamental organelle and it is essential for the cell homeostasis. Vitamin C appears to contribute to this through reducing generated ROS, which stabilizes the mitochondrial membrane [31].

Julia Kaźmierczak-Barańska et al., 2020 added that vitamin C play an important part in cellular defense against oxidative stress because of their capacity to bind and neutralize to the formed ROS, which ultimately lead to avoiding DNA damage, lipid oxidation and mitochondrial destruction [16].

\section{Conclusion}

AgNPs produced substantial toxic histopathological changes in the submandibular salivary glands of albino rats while the administration of vitamin $\mathrm{C}$ has proven to be effective in counteracting these toxic effects through its powerful antioxidant properties.

\section{References}

[1]. Jeevanandam J, Barhoum A, Chan YS, Dufresne A, Danquah MK. Review on nanoparticles and nanostructured materials: history, sources, toxicity and regulations. Beilstein J Nanotechnol. 2018 Apr 3;9:1050-1074. PubmedPMID: 29719757.

[2]. Mody VV, Siwale R, Singh A, Mody HR. Introduction to metallic nanoparticles. J Pharm Bioallied Sci. 2010; 2(4):282-289. PubmedPMID: 21180459.

[3]. Li C, Zhang Y, Wang M, Zhang Y, Chen G, Li L, et al. In vivo real-time visualization of tissue blood flow and angiogenesis using Ag2S quantum dots in the NIR-II window. Biomaterials. 2014; 35(1):393-400. PubmedPMID: 24135267.

[4]. Sharma VK, Yngard RA, Lin Y. Silver nanoparticles: green synthesis and their antimicrobial activities. Adv Colloid Interface Sci.2009; 145(1-2):8396. PubmedPMID: 18945421.

[5]. Calderón-Jiménez B, Johnson ME, Montoro Bustos AR, Murphy KE, Winchester MR, Vega Baudrit JR. Silver Nanoparticles. Technological Advances, Societal Impacts, and Metrological Challenges. Front Chem.2017; 5:6. PubmedPMID: 28271059.

[6]. Burdușel A-C, Gherasim O, Grumezescu AM, Mogoantă L, Ficai A, Andronescu E. Biomedical Applications of Silver Nanoparticles: An Up-toDate Overview. Nanomaterials (Basel). 2018; 8(9):681. PubmedPMID: 30200373.

[7]. Wang Z, Xia T, Liu S. Mechanisms of nanosilver-induced toxicological effects: more attention should be paid to its sublethal effects. Nanoscale. 2015; 7(17):7470-7481. PubmedPMID: 25865054.

[8]. Akter M, Sikder MT, Rahman MM, Ullah A, Hossain KFB, Banik S, et al. A systematic review on silver nanoparticles-induced cytotoxicity: Physicochemical properties and perspectives. J AdvRes. 2018;9:1-16. PubmedPMID: 30046482 .

[9]. AshaRani PV, Low KahMun G, Hande MP, Valiyaveettil S. Cytotoxicity and genotoxicity of silver nanoparticles in human cells. ACS nano. 2009; 3(2):279-290. PubmedPMID: 19236062 
[10]. Liao C, Li Y, Tjong SC. Bactericidal and Cytotoxic Properties of Silver Nanoparticles. Int J Mol Sci. 2019; 20(2). Pubmed PMID: 30669621.

[11]. Zapór. Effects of silver nanoparticles of different sizes on cytotoxicity and oxygen metabolism disorders in both reproductive and respiratory system cells. Archives of Environmental Protection. 2016; 42(4):32-47.

[12]. Mao B-H, Chen Z-Y, Wang Y-J, Yan S-J. Silver nanoparticles have lethal and sublethal adverse effects on development and longevity by inducing ROSmediated stress responses. Scientific Reports. 2018; 8(1):2445.Pubmed PMID: 29402973.

[13]. Lee B, Lee MJ, Yun SJ, Kim K, Choi IH, Park S. Silver nanoparticles induce reactive oxygen species-mediated cell cycle delay and synergistic cytotoxicity with 3-bromopyruvate in Candida albicans, but not in Saccharomyces cerevisiae. IntJNanomedicine. 2019;14:4801-4816. PubmedPMID: 31308659.

[14]. Ansar S, Alshehri SM, Abudawood M, Hamed SS, Ahamad T. Antioxidant and hepatoprotective role of selenium against silver nanoparticles. IntJNanomedicine. 2017; 12:7789-7797.Pubmed PMID: 29123393.

[15]. Abd El-Maksoud EM, Lebda MA, Hashem AE, Taha NM, Kamel MA. Ginkgo biloba mitigates silver nanoparticles-induced hepatotoxicity in Wistar rats via improvement of mitochondrial biogenesis and antioxidant status. Environ SciPollut Res Int.2019; 26(25):25844-25854.Pubmed PMID: 31267406

[16]. Kaźmierczak-Barańska J, Boguszewska K, Karwowski BT. Nutrition Can Help DNA Repair in the Case of Aging. Nutrients. 2020; 12(11).Pubmed PMID: 33139613.

[17]. Faul F, Erdfelder E, Lang A-G, Buchner A: G*Power 3. A flexible statistical power analysis program for the social, behavioral, and biomedical sciences. Behav Res Methods.2007, 39:175-191. PubmedPMID: 17695343.

[18]. El Mahdy MM, Eldin TA, Aly HS, Mohammed FF, Shaalan MI. Evaluation of hepatotoxic and genotoxic potential of silver nanoparticles in albino rats. ExpToxicolPathol. 2015; 67(1):21-29.Pubmed PMID: 25446800.

[19]. Ergul Y, Erkan T, Uzun H, Genc H, Altug T, Erginoz E. Effect of vitamin C on oxidative liver injury due to isoniazid in rats. Pediatr Int. 2010; 52(1):6974.Pubmed PMID: 19496975.

[20]. Osborne OJ, Johnston BD, Moger J, Balousha M, Lead JR, Kudoh T, Tyler CR. Effects of particle size and coating on nanoscale $\mathrm{Ag}$ and $\mathrm{TiO}_{2}$ exposure in zebrafish (Daniorerio) embryos. Nanotoxicology. 2013; 7(8):1315-1324. Pubmed PMID: 23035978.

[21]. Sarhan OMM, Hussein RM. Effects of intraperitoneally injected silver nanoparticles on histological structures and blood parameters in the albino rat. IntJ Nanomedicine. 2014;9:1505-1517. PubmedPMID: 24711700.
[22]. Taha RM, Said RHM. Possible cytotoxic effects of silver nanoparticles on the parotid glands of albino rats. Egyptian Dental Journal. 2019; 65(4):22532263.

[23]. Ashraf B, Ghazy D, Shamel M. Effects of aflatoxin B1 on the submandibular salivary gland of albino rats and possible therapeutic potential of Rosmarinus officinalis: a light and electron microscopic study. F1000Research. 2020;9:752. PubmedPMID: 32789012.

[24]. Taghyan SA, Messiry HE, Zainy MAE. Evaluation of the toxic effect of silver nanoparticles and the possible protective effect of ascorbic acid on the parotid glands of albino rats: An in vivo study. ToxicolInd Health.2020;36(6):446-453. PubmedPMID: 32546121.

[25]. Ma W, Jing L, Valladares A, Mehta SL, Wang Z, Li PA, et al. Silver nanoparticle exposure induced mitochondrial stress, caspase- 3 activation and cell death: amelioration by sodium selenite. Int J Biol Sci. 2015; 11(8):860-867. PubmedPMID: 26157341

[26]. Liu X, Lee PY, Ho CM, Lui VC, Chen Y, Che CM, et al. Silver nanoparticles mediate differential responses in keratinocytes and fibroblasts during skin wound healing. ChemMedChem. 2010; 5(3):468-475. PubmedPMID: 20112331.

[27]. Carr AC, Maggini S. Vitamin C and Immune Function. Nutrients. 2017; 9(11):1211.Pubmed PMID: 29099763

[28]. Guo D, Zhu L, Huang Z, Zhou H, Ge Y, Ma W, et al. Anti-leukemia activity of PVP-coated silver nanoparticles via generation of reactive oxygen species and release of silver ions. Biomaterials. 2013; 34(32):7884-7894. PubmedPMID: 23876760.

[29]. Suliman YA, Ali D, Alarifi S, Harrath AH, Mansour L, Alwasel SH. Evaluation of cytotoxic, oxidative stress, proinflammatory and genotoxic effect of silver nanoparticles in human lung epithelial cells. Environ Toxicol. 2015; 30(2):149-160.Pubmed PMID: 23804405.

[30]. Teodoro JS, Silva R, Varela AT, Duarte FV, Rolo AP, Hussain S, Palmeira CM. Low-dose, subchronic exposure to silver nanoparticles causes mitochondrial alterations in Sprague-Dawley rats. Nanomedicine. 2016; 11(11):1359-1375. PubmedPMID: 27171910.

[31]. Kc S, Cárcamo JM, Golde DW. Vitamin C enters mitochondria via facilitative glucose transporter 1 (Glut1) and confers mitochondrial protection against oxidative injury. FASEB J. 2005 Oct;19(12):1657-67. Pubmed PMID: 16195374. 